\title{
José Zapiola como escritor y los inicios de la crítica musical y de la musicografía en Chilel.
}

\section{José Zapiola as Writer in the Beginnings of Musical Criticism and Writing on Music in Chile.}

\author{
por \\ Cristián Guerra Rojas \\ Facultad de Artes, Universidad de Chile \\ cristianguerrar@gmail.com
}

El presente artículo aborda la figura del músico chileno José Zapiola Cortés (1802-1885) como escritor y su contribución en los inicios de la crítica musical y de la musicografía en Chile. La hipótesis es que Zapiola no fue un hombre de letras sino que un músico letrado, que, por razones familiares y sociales, buscó afirmar su identidad personal y profesional en el mundo de la música, dentro del marco de la imposición del proyecto de la modernidad en Chile. Sobre esta hipótesis se busca explicar las ideas que aporta en sus libros La Sociedad de la Igualdad y sus enemigos, Recuerdos de treinta años y sus comentarios en el Semanario Musical (1852). En ellos Zapiola sienta las bases no solamente de una crítica musical propiamente tal, sino de una crítica de la institucionalidad musical, especialmente en el caso del Conservatorio Nacional de Música fundado en 1849.

Palabras claves: José Zapiola, modernidad, música chilena del siglo XIX, crítica musical, Conservatorio Nacional de Música (Santiago, Chile).

This article deals with the Chilean musician and writer Jose Zapiola Cortés (1802-1885) and his contribution in the beginnings of both musical criticism and musicography in Chile. As a hypothesis it is put forward that Zapiola was not a man of letters but a musician of letters, who, because of family and social reasons, tried to build his personal and professional identity in the Chilean music milieu, at the time when the project of modernity was established in Chile. On the basis of this hypothesis, the ideas that he presents in his books La Sociedad de la Igualdad y sus enemigos, Recuerdos de Treinta Años and his commentaries in the Semanario Musical are analyzed. In these works, Zapiola prepared the ground for both a proper musical criticism and a criticism of musical institutions in Chile, specially in the case of the National Conservatory of Music founded in 1849.

Key words: José Zapiola, modernity, Chilean $19^{\text {th }}$ century music, musical criticism, National Conservatory of Music (Santiago, Chile).

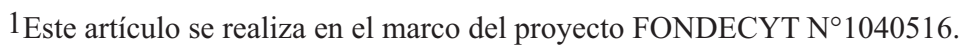

Revista Musical Chilena, Año LXII, Santiago de Chile, Enero-Junio, 2008 N²09 


\section{INTRODUCCIÓN}

Sin duda uno de los grandes aportes de la modernidad en Latinoamérica y en el resto del mundo, entendido este concepto "en términos del modelo anglosajón e ilustrado que propugna la emancipación de la razón, la autonomía de las esferas socioculturales (política, economía, arte, religión) y la creencia en el progreso ilimitado de la sociedad humana, favorecido por esta circunstancia ${ }^{2}$, es la expansión del acceso hacia la alfabetización, la lectura y la escritura. Este proceso ciertamente no estuvo exento de dificultades, desigualdades y un sinnúmero de temas pendientes hasta el día de hoy, pero, en consonancia con los planteamientos de Ángel Rama, la ciudad letrada se impuso en nuestro continente.

Un aspecto interesante de este proceso fue el surgimiento y desarrollo de la musicografía y de la crítica musical en gran parte de Latinoamérica. Por musicografía se puede entender en general toda escritura sobre música, comprendida ésta como práctica social o como obras musicales, respecto a compositores, intérpretes o audiencias, o sobre aspectos estéticos, históricos, sociales o de diversa índole. La musicología y la crítica musical, en tanto escritura, pueden considerarse como casos específicos y especializados de musicografía. Por su parte, la crítica musical puede entenderse como el análisis profundo de una obra o evento musical desde una perspectiva teórica o estética determinada, que implica un dominio efectivo de la materia.

La musicografía y la crítica musical suelen ser ejercidas tanto por músicos como por no-músicos, en tanto, estos últimos, como personas entendidas pero no profesionales del área. Y en el caso de los músicos que escriben sobre música, por definición se trata de músicos letrados: compositores o intérpretes musicalmente alfabetizados (leen y escriben música) y además competentes para hablar (y escribir) sobre música. Este último es el caso de José Zapiola, importante músico chileno del siglo XIX, cuya contribución al desarrollo de estas actividades en Chile abordo a continuación. Para ello, examinaré sucintamente sus tres obras literarias de mayor envergadura: La Sociedad de la Igualdad y sus enemigos, el Semanario Musical y Recuerdos de treinta años, y después pasaré a considerar sus aportes específicos en los ámbitos indicados, a partir de la hipótesis que Zapiola es un músico letrado que buscó crear(se) un espacio legítimo dentro de la ciudad letrada.

\section{ZAPIOLA, MÚSICO LETRADO.}

José Luis Zapiola Cortés (1802-1885) no era un hombre de letras, sino un músico letrado. Un músico que como individuo ganó prestigio y reconocimiento en la sociedad chilena durante las primeras décadas del siglo XIX. Sin embargo, el lugar del músico dentro del proyecto de país que se proponía establecer era bastante desmedrado. Ciertamente había y siempre ha habido música vinculada con ocasiones y eventos importantes, de alta significación social, pero el lugar del músico y su papel en la formación de la sociedad chilena no había sido asumido en la época de Zapiola, al menos no en los términos que él esperaba por parte de la clase o elite dirigente.

Aunque en su juventud se vinculó con el ala liberal de esta clase dirigente, integró la Sociedad de la Igualdad, escribió un opúsculo en su favor y hasta sufrió la pena de

2Guerra 2006: 49-50. 
extrañamiento tras el fracaso de la revolución de 1851, Zapiola en el fondo no se consideraba "uno de ellos". Y aunque después se acercó al partido conservador, que de hecho lo llevó a ocupar el cargo de regidor en Santiago entre 1870 y $1872^{3}$ y lo estimuló para escribir sus Recuerdos, a modo de ataque contra el proyecto liberal de construcción nacional, tampoco se integró plenamente a este sector.

Una de las explicaciones que se puede aducir es la circunstancia que Zapiola era hijo natural de un abogado argentino, lo que implicó que desde su infancia estuviese en el margen de la sociedad, al menos de la "sociedad de buen tono". O para ser más precisos, aquella sociedad republicana que, en contraposición al período colonial, excluyó a la madre soltera, a su hijo (el huacho) y a las uniones "ilegítimas" de su modelo familiar, o al menos de su discurso sobre éste ${ }^{4}$. Al respecto, es interesante la observación de César Díaz-Cid ${ }^{5}$ sobre el relato que hace Zapiola en sus Recuerdos respecto a la adquisición de su primer clarinete: el mate de plata que vendió su madre para comprar el instrumento, sería una representación del "desprendimiento por parte del sujeto, del recuerdo de la imagen paterna, sobre todo si se considera al mate como representación simbólica que conecta la 'alhaja' familiar con 'lo argentino"'.

En segundo lugar, era músico, oficio requerido y solicitado en múltiples ocasiones, pero que no tenía bajo ningún concepto el rango del hombre de letras, el abogado, el escritor o el poeta en la "ciudad letrada" que la elite dirigente, en vertiente conservadora o liberal, construía ${ }^{6}$. Como afirma Díaz-Cid ${ }^{7}$, Zapiola buscó su legitimación social desde la música, lo que habría constituido otro "apartarse radical de las opciones de vida asumidas por su progenitor". Sin embargo, Zapiola no sólo aprendió a tocar clarinete u otros instrumentos, sino a leer y escribir música, a componer, a manejar los códigos de notación musical que permiten, precisamente, constituir a sus expertos en una "ciudad letrada de la música". Junto con esto, al formarse musicalmente en el mundo de las bandas militares y por medio de ellas participar en la gesta emancipadora, Zapiola buscó afirmar su legitimación en la heroicidad en tanto "soldado de la Independencia 8 , estrategia que se trasluce en un nuevo contexto como miembro de la "rebelde" Sociedad de la Igualdad y que coincide con los modos de autoafirmación social que las clases bajas y los huachos desplegaron en Latinoamérica y Chile durante el siglo XIX9

\subsection{La Sociedad de la Igualdad y sus enemigos.}

Zapiola fue uno de los miembros fundadores de la Sociedad de la Igualdad en 1850, al igual que Santiago Arcos, Francisco Bilbao, Eusebio Lillo y los obreros Cerda y Ambrosio Larrecheda. Junto a Arcos redactó los estatutos y el reglamento de la organización, y fue miembro de su junta directiva. Posteriormente, debido a los sucesos acontecidos en la transición del gobierno de Manuel Bulnes al de Manuel Montt, que Cristián Gazmuri ha

\footnotetext{
3Pereira Salas 1945a: 32.

4Montecino 1993: 51-52.

5Díaz-Cid 2002: 199; Díaz-Cid 2004.

6De hecho, el padre de Zapiola era abogado y se negó a reconocerlo como hijo al enterarse que se había dedicado a la música. Un dato que, creemos, no es menor para comprender la ambivalencia del músico huacho frente al proyecto social del patriarcado letrado.

7 Díaz-Cid 2004.

8Walker 1889: 217. Carlos Walker Martínez era el director de El Independiente, donde Zapiola publicó algunos de los artículos que articularían posteriormente sus Recuerdos de treinta años.

9Rama 1984: 104; Montecino 1993: 56, 142.
} 
denominado acertadamente como "el 48' chileno", la Sociedad fue disuelta y varios de sus líderes y miembros sufrieron pena de exilio o extrañamiento. Éste último fue el caso de Zapiola, relegado a la isla de Chiloé por breve tiempo.

En La Sociedad de la Igualdad y sus enemigos, Zapiola defiende los propósitos altruistas de la Sociedad y niega cualquier vínculo entre ella y los actos violentos que se le atribuyeron. Antes bien, esta organización se presenta como una entidad que no reconocía diferencia de clases para la participación de sus miembros: intelectuales liberales radicales, de cuna aristocrática y burguesa, se aliaron con sectores populares a favor de un cambio social radical que permitiera así el establecimiento de una república de hombres libres e iguales. En este marco, la Sociedad de la Igualdad implementó un proyecto de escuela vespertina gratuita que contemplaba doce asignaturas, entre ellas música y baile, a cargo de Zapiola. Este proyecto tenía el propósito de contribuir a la elevación educativa, moral e intelectual de la clase obrera, el "bajo pueblo"10:

"Con excepción de dos, todas estas clases fueron abiertas a fines de Setiembre con mas de trescientos alumnos, cuyo número se dobló antes de dos semanas. Los profesores eran los ciudadanos Santa María, Marín, Recabarren, Villegas, Maturana, Castillo, Moore, Rojas Ramírez i Zapiola.

Era un espectáculo hermoso el que presentaban aquellos vastos salones llenos de hombres que acababan de salir de su trabajo i que en lugar de ir a pasar el tiempo en la ociosidad o de un modo aun mas pernicioso, lo consagraban al cultivo de su inteligencia con una atención i esmero que enternecia a los espectadores. Muchas veces nos preguntamos ¿dónde pasan este tiempo ahora gran parte de estos hombres? La respuesta es desconsoladora para nosotros [...]"

Lo importante de este párrafo es que trasunta una idea rectora en la implementación de la enseñanza de la música en particular: su capacidad de "cultivar la inteligencia", de elevar el nivel moral y social de las personas. Los antecedentes de este planteamiento ya se pueden encontrar en José Joaquín de Mora, Andrés Bello y Domingo Faustino Sarmiento, y está en la base del proyecto educativo de la Cofradía del Santo Sepulcro, como se verá más adelante.

\subsection{El Semanario Musical.}

El Semanario Musical fue la primera publicación especializada en música de Chile y toda Latinoamérica, tuvo 16 números (publicados entre el 10 de abril y el 24 de julio de 1852) y José Zapiola participó en su elaboración. Varios capítulos sobre música en los posteriores Recuerdos de treinta años son revisiones de artículos escritos originalmente para el Semanario Musical. Éste se publicaba en Santiago, en la imprenta del francés Julio Belin, yerno de Domingo Faustino Sarmiento y radicado en Chile desde 1848. En su redacción participaron principalmente Zapiola, Francisco Oliva y después José Bernardo Alzedo, de acuerdo al testimonio que el propio Zapiola dejó en su carta autobiográfica a José Bernardo Suárez de 1872.

Sin embargo, en esta publicación hubo además contribuciones de Isidora Zegers, su hija Flora Tupper Zegers y “A.F.S.”. Isidora Zegers aportó con traducciones y el

10Zapiola 1902: 29

11Esta información la proporciona Isidora Zegers en notas manuscritas que escribió en los márgenes de varias copias de los 16 números del Semanario Musical, las que conservó en un álbum privado que hoy forma parte de los papeles de Eugenio Pereira Salas. Barth (1970) no tuvo acceso a esta fuente. 
folletín "Historia del origen de la ópera italiana en Francia" en los números 15 y 16. Flora Tupper realizó la traducción al castellano del trabajo "La imagen de Nuestra Señora ${ }^{11}$, original del escritor francés Jules Rostaing, publicada en los números 12, 13 y 14. En cuanto a "A.F.S.", es la sigla que identifica al traductor de "Historia de los instrumentos musicales", una obra original en francés de F. J. Fétis que se publicó en casi la totalidad de los números publicados del Semanario Musical. Creo que la identidad de "A.F.S." corresponde a Ana Faustina Sarmiento, hija de Domingo y esposa de Julio Belin, la que a la sazón tenía veinte años y había recibido una esmerada educación por parte de su padre, lo que le habría permitido abocarse a la tarea de traducción. Además, es interesante notar que este trabajo culmina -aunque no está debidamente explicitado- en el $\mathrm{N}^{\circ} 16$, último número publicado del Semanario. Esto puede indicar que el interés de Belin en asumir la publicación de este periódico -de precario sostén económico- estuvo directamente vinculado con el aporte de su mujer y una vez acabado éste, suspendió su apoyo.

En el primer número del Semanario Musical $^{12}$ se publicaron sus propósitos, fundamentalmente dos: informar e instruir. Informar sobre el acontecer musical e instruir sobre las peculiaridades técnicas de la música. En este marco, en el mismo primer número se publicaron definiciones "del arte", "de la música" y "de la materia de la música", definiciones cuya matriz estética indudablemente compartían los redactores de la revista. En este marco además se inscribe la publicación de los "Apuntes para la historia de la música en Chile", donde hallamos la primera versión de algunos capítulos claves de Recuerdos de treinta años. Es aquí, entonces, donde se puede identificar el aporte más importante de Zapiola en los orígenes de la musicografía y de la crítica musical en Chile, como se verá más adelante.

\subsection{Recuerdos de treinta años.}

Con sus Recuerdos de treinta años, José Zapiola es uno de los fundadores del género memorialista en Chile, junto a Vicente Pérez Rosales y a José Victorino Lastarria. E1 origen de esta obra se encuentra en algunos artículos que aparecieron en el Semanario Musical bajo el título de "Apuntes para la historia de la música en Chile" y en otros que se publicaron en los periódicos La Estrella de Chile en 1867 y en 1872-78 y El Independiente en 1879-83, compilados en dos partes que se publicaron juntas por primera vez en $1881^{13}$.

Díaz-Cid ${ }^{14}$ califica los textos autobiográficos como híbridos entre historia y literatura, lo cual les permite dialogar con diferentes discursos. En el caso de la práctica autobiográfica de la segunda mitad del siglo XIX, uno de sus propósitos frecuentes es la contestación al discurso historiográfico que voces como las de Miguel Luis Amunátegui Aldunate, Benjamín Vicuña Mackenna o Diego Barros Arana instalan en aquellos años. Aquí se inscriben los casos de Vicente Pérez Rosales, José Victorino Lastarria y José Zapiola, ante los cuales aparece el referente de Domingo Faustino Sarmiento y sus Recuerdos de provincia ${ }^{15}$. Pero Zapiola tiene una particularidad: a diferencia de Pérez Rosales y de Lastarria, Zapiola deviene un "sujeto adánico (esto es, sujeto cuyos recuerdos de infancia coinciden con los inicios de la república)" que no pertenece a la clase dominante, aquella

\footnotetext{
12 Semanario Musical, $\mathrm{N}^{\circ} 1$ (10 de abril, 1852), p.1.

13Pereira 1945a: 34-36, 302-303.

14Díaz-Cid 2002: 191; Díaz-Cid 2004.

15 Cuya primera edición data de 1850, Santiago, imprenta de su yerno Julio Belin. Como observa Díaz Cid (2002; 2004), en los Recuerdos de treinta años hay referencias intertextuales muy peculiares hacia esta obra.
} 
elite que en los albores de la república, pese a la existencia de facciones y corrientes ideológicas más o menos diferentes, actuaba dentro de un marco consensuado en torno a los conceptos de república, orden social y religión católica ${ }^{16}$.

Creo que una de las razones por las cuales Zapiola decidió incursionar en las letras mediante sus Recuerdos, incursión precedida fundamentalmente por su labor en el Semanario Musical, se relaciona directamente con este tema y además con su disgusto frente al modo en que sus antiguos camaradas liberales reconstruían el pasado de la nación. Pero además, en la génesis de esta obra advierto un proceso que no me deja de resultar semejante a la manera con que a menudo se escribían o reescribían óperas y espectáculos teatrales en aquella época: una sucesión de adiciones, sustracciones, modificaciones, adaptaciones que complican en gran medida la delimitación de una versión o edición definitiva de este tipo de obras. Zapiola era un profesional formado en el teatro y no solamente en el aspecto musical, sino en el literario. De hecho, en su estudio inédito sobre Zapiola, Jorge Urrutia considera, siguiendo a Ventura Blanco, que fue precisamente en la ópera y el teatro donde este músico encontró el espacio que le permitió formarse como "músico letrado" a cabalidad:

"Podríamos presumir que en gran parte pudo ser su obligada asistencia a incontables representaciones teatrales, una fuente de educación literaria para nuestro músico. No olvidemos que ya desde 1820 -o sea a los 18 años- declara en sus 'Recuerdos' que actuaba como clarinetista en la infaltable orquesta que entonces siempre amenizaba los espectáculos teatrales. Y después le cupo a menudo colaborar en actividades profesionales análogas.

Esto lo destaca precisamente don Ventura Blanco en la interesante introducción que hace a los 'Recuerdos de Treinta Años' de Zapiola, en diciembre de 1872. Allí dice lo siguiente, que nos llevó a presumir lo expresado: 'Sentado en el escaño de los músicos, fue el teatro su escuela literaria. Leyendo hoy lo que la crítica dice del drama de ayer, reflexionando mañana, a la luz de sus consejos y de sus lecciones, en el momento en que se repite la pieza en cuestión, fue el proscenio para nuestro amigo lo que el gabinete anatómico para el estudiante, en donde con el escapelo [sic] en la mano analiza y estudia y aprende a conocer el variado e inexplicable mecanismo de la máquina humana.

Es el proscenio una escuela terrible, aún para los que lo miran desde afuera. En un mundo con todas las seducciones de la apoteosis, que mucho de las apoteosis tienen los triunfos del artista, que enloquece con su talento a un público sediento de novedad y de encantos, con todos los peligros de Scila y Caribdis, que tal es la volubilidad del público que ayer conducía en triunfo a un artista al Capitolio y hoy lo arrastra con escarnio a las Gemonias'. En resumen, reiteramos que de esta forma Zapiola fue un caso chileno de formidable asimilación. Y en el doble campo de la música y las letras".

Esta formación peculiar de Zapiola le permitió comprender las dificultades prácticas que a menudo debían sortearse para montar una obra dramática, especialmente una obra dramático-musical: el cambio de algunos números según los requerimientos de los cantantes, la adaptación de la instrumentación de acuerdo a los medios efectivamente disponibles e incluso la creación de números nuevos por combinación de ambos factores. Más adelante citaré algunos comentarios de Zapiola publicados en el Semanario Musical que corroboran este aserto. Lo que aquí destaco es que un principio similar rige la gestación de los Recuerdos de treinta años: artículos que se publicaron en distintos periódicos, recopilaciones seguidas de nuevos artículos sueltos, nuevas recopilaciones con adiciones o supresiones de los escritos publicados en los periódicos o en ediciones anteriores, ajustes y enmiendas de datos factuales, etc. Por lo tanto, la complejidad de este proceso ${ }^{17}$ plantea la necesidad de

16Stuven 2000: 29-60; cf. Rama 1984: 100-101.

17Proceso que se puede advertir con cierto detalle en Pereira Salas $1945 \mathrm{~b}$. 
realizar algún día una edición crítica y "abierta" que considere la inclusión, por lo menos a modo de complemento, tanto de artículos "desechados", como "Un rasgo de fidelidad en el servicio" o "El gato de palacio", así como de un detalle de las enmiendas hechas en el texto a través de ediciones sucesivas.

\section{ZAPIOLA COMO CRÍTICO MUSICAL.}

Spencer ${ }^{18}$ indica que la crítica musical "ha tenido y tiene hoy una doble función en la vida musical del país". Por un parte, una función pedagógica y formativa, que favorece el enriquecimiento del público en temas musicales, interpretación, composición, etc., y por otra, una función documental, en tanto "se convierte, por la acción de la escritura, en un documento histórico". En el caso de la crítica musical, el aporte de José Zapiola representa un hito en el sentido de la aparición de un discurso sobre la música fundamentado en los aspectos técnicos y prácticos de ésta, a diferencia de lo que se aprecia, a grandes rasgos, en los escritos pertinentes de Bello o Sarmiento. Mientras estos últimos plantean los grandes marcos ideológicos, artísticos o culturales en los que se inscribe la actividad musical, especialmente la ópera, el "deber ser", Zapiola aporta un necesario complemento, que es el "cómo se hace". Y esto sucede en una época en que el espacio de la opinión pública crece, las disensiones comienzan a perfilarse y los grandes consensos frente al proyecto de país empiezan lentamente a desdibujarse.

De acuerdo a la teoría de los linajes espirituales en la crítica literaria de Hyman y Martins, aplicada al caso chileno por Dyson ${ }^{19}$ Bello inauguró el linaje humanista de la crítica literaria en Chile y lo mismo podríamos afirmar respecto a la crítica musical, como se desprende del estudio del Dr. Luis Merino ${ }^{20}$. Sarmiento también se vincula con este linaje. En cambio, Zapiola fue el fundador de los linajes histórico y gramaticalmusical, en el sentido de atender tanto a aspectos técnicos como históricos de la práctica social de la música en Chile, profundizando así los enfoques de sus predecesores, como el caso de Bello21.

Como señala Julia Grandela ${ }^{22}$, Zapiola comenzó su actividad como escritor a una edad madura, pasados los cuarenta años. Su primera incursión en este terreno fue en 1844, en su "Carta a los Aficionados" inserta en El Siglo ${ }^{23}$, donde otorga una explicación técnica acerca de las variaciones de su instrumento, el clarinete, en la famosa "escena del delirio" de Lucía de Lammermoor de Donizetti24. Es decir, antes de escribir La

18Spencer 2002: 6

19Dyson 1965.

20Merino 1981a. Este trabajo, publicado en la Revista Musical Chilena, aparece además en el volumen Homenaje a don Andrés Bello, Santiago: Instituto de Chile y Editorial Andrés Bello, 1982, pp. 187-234. "Don Andrés Bello y la música", Revista Musical de Venezuela, II/5 (septiembre-diciembre), pp.13-68.

21 Merino 1981: 34. Se debe recordar que Bello fue uno de los primeros en valorar públicamente a Zapiola como músico (ibid.: 25).

22 Grandela 1999.

23Pereira Salas y Urrutia indican el 22 de abril de 1844 como fecha de la edición del número de El Siglo en que se publicó este escrito de Zapiola. Sin embargo, ni en las investigaciones llevadas a cabo por el Dr. Luis Merino ni en las mías se ha localizado este artículo en la edición mencionada.

24Pereira Salas 1945b: 299. 
Sociedad de la Igualdad y sus enemigos, el primer trabajo publicado de Zapiola resulta ser un escrito musicográfico: Zapiola comienza a escribir a partir de la música y más concretamente, de su propia práctica musical como clarinetista.

A continuación, corresponden sus escritos específicos en el Semanario Musical. Algunas críticas aparecen firmadas con el seudónimo "Crecendo Veritalli", con el cual se presenta en la sección "Correspondencia" en el No $9^{25}$ de este periódico:

\section{“SS. EE del Semanario Musical.}

Remito a UU un artículo que solo es la introducción de otros que me propongo escribir. Compongo parte de la ópera, i por lo tanto estoi al cabo de muchas cosas que no carecerán de interés.

\section{INTRODUCCION A MIS ARTÍCULOS.}

Entro entonando a lo poeta épico: acudid, Musas, pues las voi a tener con toda una compañía lírica; item mas con algunos de los 15 músicos de que se compone la orquesta de esta: me consta que voi a acarrearme un mundo de enemigos; me consta que tengo que lidiar con una hueste defensora de sus regalías a todo trance. Pero nada me ataja, pues tengo que desempeñar un jeneralato sagrado. No me faltará esfuerzo para recabar mi intento, aun cuando me cupiese la corona del martirio. Principiaré por denunciar a Vds un descuido de los empresarios; sin duda estos señores no se han fijado en lo que el público vé todas las noches con desagrado. Es el caso SS. EE que se entra no sé si volando, o arrastrando las alas, cierto pájaro nocturno i va a colocarse inmediato a la araña, sin duda al olor del aceite que esta contiene, i como es ave que gusta mucho de este líquido, i no siéndole fácil estraerlo del depósito que lo contiene, dá tanto i tan repetidos aletazos que incomoda a todos los concurrentes. Bien podian pues los Empresarios, espantar dicho pájaro para no dar lugar a que el público se distraiga i no preste la debida atención a la música. No les diré mucho en esta correspondencia del abuso que hacen algunas personajes de la Compañía de los rallentandos; de la monotonía en los Calderones, lo poco que se cuidan de aprender bien los recitados en las óperas bufas (sin embargo de los muchos grandes tijeretazos que se les dá); ni tampoco me alargaré demasiado, si les digo que la instrumentación de algunas óperas (i las de Verdi sobre todo) carece de fuerza i de ese bello colorido que le dá este célebre compositor a sus particiones; esto creo que me dará materia suficiente para otro artículo, i por eso quiero reservarlo para después. De paso les diré que hagan ustedes lo posible para que la extremidad izquierda de la orquesta observe mas los pianos que los fuertes, i que las trompas hagan con mas exactitud sus entradas, pues que he oido muchas veces que lo hacen uno o dos compases después.

En fin, SS. EE por esta vez quiero despedirme ya porque me parece que he copiado algunas de las grandes fantasías del célebre Thalberg, según lo largo que me está pareciendo este artículo, pero no por esto desea servirles menos que ántes, su afectísimo amigo,

Crecendo Veritalli."

25Semanario Musical, $\mathrm{N}^{\circ} 9$ (5 de junio, 1852), pp.2-3. 
Este seudónimo de Zapiola alude por un lado a la devoción por Rossini ("El Señor Crescendo") y por otro lado al propósito de "crecimiento (difusión) de la verdad" acerca de la práctica musical -específicamente de la ópera- en la naciente república y los modos de mejorarla, es decir, los propósitos mismos del Semanario. En otras palabras, como plantea Spencer, la escritura musicográfica y crítica de Zapiola deviene tanto testimonio de un propósito educador como documento de las prácticas musicales que la sociedad chilena, o más bien su elite -a la que se dirige Zapiola- estimaba relevantes, entre las cuales la ópera ocupaba el lugar principal. El punto es que Zapiola buscaba plasmar "desde dentro", desde el quehacer musical mismo, su análisis de la realidad. De este modo, Zapiola opina sobre la interpretación de las óperas La hija del regimiento (1840) y María de Rohan (1843) de Donizetti (Semanario Musical $\left.\mathrm{N}^{\circ} 10^{26}\right)$, así como de $I$ Masnadieri (1847) de Verdi (Semanario Musical $\mathrm{N}^{\circ} 11^{27}$ ):

"LA HIJA DEL REJIMIENTO.

Esta ópera de Donizetti, se dio por primera vez en esta temporada, el jueves tres con una regular concurrencia.

Por esta vez, el rejimiento del cual es hija la prima Dona en esta ópera, ha sido un rejimiento recluta, eceptuando a Tonio que comprende bien el carácter que representa, sea cual fuere el papel que desempeñe.

No gusto mucho de hacer comparaciones i por esto no digo nada del modo como hacía esta ópera la compañía francesa, i como la desempeña la actual compañía italiana. El público que la ha visto representar por ambas, sabrá cuál es la que la ha desempeñado con más perfección.

\section{MARIA DE ROHAN.}

Esta es otra de las óperas de Donizetti que dio la compañía francesa i si he de dar mi opinión francamente, diré que en la compañía italiana están mejor espresados los diversos sentimientos, aparecen más en relieve las ideas sublimes que el maestro ha sabido dar a esta composición; esto es en cuanto a los primeros roles, que por lo que respecta a los coros, es mucha la falta que hace, la octava alta del coro de mujeres en todas las óperas que da la actual compañía; lo que hacía aparecer de otro color en la compañía francesa cualesquiera coro por pequeño que fuese. ¿Y qué diré de todos los grandes finales que tienen muchas óperas italianas? ¿Qué diferente sería el efecto que producirían, si fuesen acompañadas por los coros tiples! Es sabido que suprime siempre la compañía italiana los coros de mujeres, por la sencilla razón de que carecen de ellos. Bien podían siquiera por el buen nombre que tiene la música italiana en todo el mundo, i para aproximarse un poco al modo como son representadas estas mismas óperas en Europa, agregar a los coros, tres o cuatro mujeres que creo no faltarían en la Compañía. En esto se harían mucho bien los mismos artistas, por cuanto los trozos de conjunto saldrían mejor, i entonces el público intelijente gustaría mucho más de la música i aplaudiría con más frecuencia.

Cuando dije en mi correspondencia anterior, que en algunas óperas la instrumentación, carecía de fuerza i colorido, estuve mui distante de ofender al Sr. Neumane, afortunadamente sé el talento i conocimientos que requiere dicho trabajo, para apreciarlo como merece; i ciertamente es preciso ser todo un artista, i tener toda la memoria del Sr. Neumane para hacerlo del modo como lo hace él, es decir sin partitura, trabajo que, si he de dar mi opinión imparcial en esta materia, diré que tal vez es el primer artista en Chile, que instrumenta una ópera de este modo.

Por otra parte, no negará el Sr. Neumane que, por lo menos, se necesita haber oído dos o tres veces una buena partición orijinal i ejecutada por una orquesta completa, para poder instrumentar después por la parte de piano i canto, i hacer una partición parecida al orijinal, es decir, intercalar todas las combinaciones de los instrumentos de viento, colocar en su respectivo lugar todas las invenciones de que se valen los compositores, para hacer más variada la

26Semanario Musical, $\mathrm{N}^{\circ} 10$ (12 de junio, 1852), pp. 3-4.

27 Semanario Musical, $\mathrm{N}^{\circ} 11$ (19 de junio, 1852), p.3. 
música, etc., las cosas que como lo sabe el Sr. Neumane, no pueden aparecer todas en las particiones de piano.

He tenido la fortuna de oir en Santiago, algunas instrumentaciones de Mercadante, Donizetti i Verdi i como en materia de música, me gusta atisbar hasta las cosas más insignificantes porque me sirve de mucho, no he dejado de encontrar algunos vacíos en ciertas partituras i sobre todo en la de I Masnadieri i por esto dije en el número 9 del Semanario que la instrumentación de algunas óperas carecían de fuerza, sin acordarme que el señor Neumane ha hecho cuasi todos estos trabajos para la mui diminuta orquesta de Valparaíso; i esto es lo mismo que hacer evolucionar una compañía de cazadores, en el patio de una casa particular. Hasta la vista S. S. E. E. Mucha suscrición, i poco trabajo les desea su afeticimo.

Crecendo Veritalli2"

Zapiola sigue, en tanto se enfoca en la ópera, una línea inaugurada por José Joaquín de Mora y por Andrés Bello, en cuanto a la importancia atribuida a esta expresión artística para la edificación de la sociedad. Tanto Mora como Bello tenían profundos conocimientos sobre ópera y es posible que Zapiola haya recibido su formación en este ámbito a partir de conversaciones con aquellos humanistas ${ }^{29}$, tal vez en las tertulias organizadas por Isidora Zegers, la gran promotora de la ópera -especialmente de Rossini- en Chile. Pero además, en el comentario anterior se revela, como se ha señalado anteriormente, el conocimiento que tenía Zapiola sobre el montaje y ejecución de una ópera, especialmente en su opinión sobre el trabajo de instrumentación del compositor y director ecuatoriano de origen alemán Antonio Neumane Marno (1818-1871), que en ese tiempo residía en Chile. La crítica aparece aquí, como dice Spencer, con su doble función. Por un lado, formadora, en tanto Zapiola nos entrega indicios sobre el modo de instrumentar una ópera (el "deber ser", en el ámbito específicamente musical), es decir, considerar tanto la versión (reducción) para canto y piano como la escucha atenta de la misma obra en su versión orquestada. Por otro lado, un documento histórico en sí mismo, por cuanto nos devela el modo en que efectivamente se hacía el trabajo de orquestación de una ópera en aquellos años: a partir de las reducciones para canto y piano facilitadas por Isidora Zegers y otros, con adaptaciones de acuerdo a los instrumentos disponibles.

En otro número del Semanario Musical, encontramos una mayor precisión técnica musical, específicamente al criticar el arreglo que Neumane hizo del acompañamiento en I Masnadieri ${ }^{30}$ :

\section{"CORRESPONDENCIA.}

I MASNADIERI.

Esta ópera del maestro Verdi fue mejor ejecutada la primera i segunda vez que la del domingo 13 del actual; sin embargo la señorita Rossi, el señor Ubaldi i Bastogi desempeñaron bien su parte, éste en su primer aria 'La sua lampada vitale' se hizo aplaudir bastante. Ya he notado que el público le aplaude a este actor los alegros enérjicos, más que los andantes, pero yo en más de una ocasión he visto que ha tenido momentos felices en los adajios.

El señor Ubaldi en el andantino de su aria 'O mio Castel paterno' conmovió bastante al público. Este joven tenor tiene bastante sensibilidad en los trozos patéticos, como muchos de sus compatriotas $i$ a fe que esto en Chile es mui apreciable diganlo si no las composiciones de Bellini i sobre todo Romeo i Julieta.

La señorita Rossi fue bastante aplaudida en el Duetto 'io t'amo, Amalia' que cantó con el señor Bastogi; i en donde el público se mostró más conocedor del mérito de lo que hacían,

\footnotetext{
28 Semanario Musical, No 10 (12 de junio, 1852), p.4.

29Merino 1981a: 30-31.

30Semanario Musical, No 11 (19 de junio, 1852), p. 3.
} 
fue en el calderón con que concluye el andantino.

En los tres roles que hace el Sr. Cavedagni da a conocer al público dos cosas, a saber: primera, su capacidad y segunda que en compañías como la que tenemos, en donde las partes de por medio son escasísimas, es menester dejar el orgullo de primer cantante, para contribuir al mejor éxito de las representaciones. Su magnífico romance lo cantó con la maestría que acostumbra.

En cuanto al Sr. Leonardi, lo desconocí porque me pareció que no era el Sacerdote de $L a$ Favorita ni el del Nabuco.

¿Sabéis señor Neumane que al decir en vuestra correspondencia del Mercurio del 10 del corriente que es mui presumible que el artículo a que aludís, haya sido escrito por persona poco competente para avanzar un juicio sobre la materia, habéis sufrido una equivocación? Porque aunque no tengo la pretensión de ser maestro ni mucho menos compositor de acompañamiento, como vos, voy a probaros que al hacer la instrumentación de I Masnadieri habeis estado un poco distraído, sobre todo al principio de la ópera.

En el sétimo compás del solo de clarinete que hay en el preludio [¿cómo podía conocer Zapiola exactamente este dato, sino solamente porque él mismo ejecutó este pasaje?], habeis dejado obrar puramente el acompañamiento, sin placar la harmonía, siquiera por las trompas, i que sin embargo de ser el penúltimo canto del primer período melódico, os habeis portado poco atento con él, pues cuasi es lo mismo que si fuera a visitaros por la última vez un amigo vuestro, i que al despedirse éste os quedaseis pegado en vuestra silla sin acompañarlo hasta la puerta.

En los cuatro primeros compases de la frase siguiente podiais haber placado también los acordes por las violas, $i$ haber hecho conocer más al auditorio que el autor comenzaba una nueva frase, i con esto llamabais más la atención i variabais el acompañamiento, que siempre es el mismo desde el principio del solo.

Más adelante, cuando el maestro hace entrar su frase accidentalmente en el tono mayor, os habeis olvidado de reforzar la harmonía igualmente con acordes placados, $i$ en esto insisto en que os habeis distraido, porque es casualmente el caso en que me he fijado más, siempre que he tenido ocasión de ver u oir alguna partitura de un maestro acreditado, i casi siempre he notado que echan mano de este recurso, pero vos demostrais haber tenido fija vuestra atención en el fuerte que viene al cuarto compás, i no habeis tenido en vista que van veinte i seis compases de un monótono acompañamiento ¿creeis que Verdi, el maestro que adorna i varia más sus acompañamientos, haya permanecido tan frío al instrumentar esta ópera i en un período como éste? Yo que lo conozco por sus obras de música mucho menos que vos, me atrevo a asegurar que no.

Viene después la aria del tenor ' $O$ mio Castel paterno' i el principio del andantino, es un caso igual al que hai en el segundo acto del Hernani, en el duettino 'Ah morrir potessi adesso' i recordareis que el autor en la partitura orijinal, ha repartido entre la masa de instrumentos de viento, los siete primeros compases del andante haciendo entrar el cuarteto en el compás siguiente, i mirad iqué bello efecto produce! Pues yo sin ser un compositor de acompañamiento hubiera hecho lo mismo, en los dos primeros compases del andantino a que aludo i en el tercero haría entrar los instrumentos de cuerda seguro de un buen efecto, pues como he dicho antes es un caso igual al del Hernani.

Siguiendo el curso de este andantino, se llega a la frase en que el cantor dice 'Amalia a te m'apresso', i no recuerdo bien, pero creo que no habeis dado a las trompas las corcheas que hacen el acompañamiento de la mano izquierda, i esto se hace tanto más preciso cuanto que el de la mano derecha lo haceis tocar por los clarinetes i flauta i como sabeis, las trompas pertenecen a la masa de instrumentos de viento. Tampoco ignorais que mientras el cuarteto hace cuatro notas en la harmonía a cuatro, la masa completa de instrumentos de viento puede hacer hasta diez i ya veis que para uno que compone acompañamientos este gran recurso no es para que lo mire con indiferencia.

Algunas razones me impiden pasar más adelante, una de ellas es que tengo más gusto cuando vhay ocasión de elojiaros vuestro indisputable mérito, que tener que relataros los olvidos que os he hecho notar. 
En cuanto a daros mi nombre como decís en vuestro artículo, quizá lo sabeis ya, i como por otra parte el nombre es mui ajeno de la cuestión me suscribo siempre con el de Crecendo Veritalli”.

Una crítica como ésta claramente puede ser realizada sólo por quien conoce el medio musical "desde dentro". Este es el punto de vista -o de audición- de Zapiola, un músico que está en el foso orquestal y desde allí puede expresar su comentario letrado-musical. Y de paso, no deja de asombrar el grado que Zapiola alcanzó en su formación autodidacta, al considerar la precisión con que realiza su análisis de la instrumentación de Neumane. El huacho que aprendió a solfear mirando atentamente los esfuerzos de su profesor de banda por descifrar las partituras que le correspondía ejecutar y cuyas salidas al extranjero se limitaron a un viaje a Argentina y un par de visitas a Perú, llegó a ser capaz de criticar la labor de un compositor, pianista y director formado en instituciones tales como el Conservatorio de Milán y con un oficio forjado en giras por Europa y Sudamérica ${ }^{31}$.

\section{ZAPIOLA COMO MUSICÓGRAFO Y CRÍTICO DE LA INSTITUCIONALIDAD MUSICAL. EL CASO DEL CONSERVATORIO NACIONAL DE MÚSICA.}

En el terreno de la musicografía, la contribución de Zapiola es fundamental en el campo de la historiografía de la música chilena. Sus mencionados "Apuntes" constituyen un antecedente fundamental e ineludible para la reconstrucción de la historia musical en Chile. Pero lo notable es que Zapiola no se limita a mirar hacia el pasado, sino también, y de un modo crítico, hacia su presente. Dicho de otro modo, Zapiola no solamente incursiona en el campo de la crítica musical en tanto crítica de obras o interpretaciones musicales, sino en el campo de la crítica de la institucionalidad musical. Y en este aspecto es digno de notarse la fuerte oposición de Zapiola, en sus primeros años, al Conservatorio Nacional de Música.

Esta última institución nació bajo el cobijo de la Cofradía del Santo Sepulcro, un organismo laico de filiación religiosa, vinculado con la estrategia del arzobispo Rafael Valentín Valdivieso a favor de la reafirmación de la iglesia católica en una nueva sociedad republicana ${ }^{32}$. Sus líderes fueron el filántropo José Miguel de la Barra y López (1802-1851) -primer decano de la Facultad de Filosofía y Humanidades de la Universidad de Chile, el abogado y diplomático Pedro Antonio Palazuelos Astaburuaga (1800-1851) -primo de Diego Portales y miembro de la Facultad de Teología- y el pintor José Teodosio Gandarillas Gandarillas (1810-1853) -miembro de la Facultad de Matemáticas- ${ }^{33}$.

En la década de 1840 el interés por implementar la enseñanza del dibujo y de la música fue tomando fuerza en la opinión pública. En este interés confluían motivaciones diversas, desde económicas y religiosas hasta intelectuales y estéticas ${ }^{34}$,

31Pereira Salas 1957: 17. En todo caso, Zapiola y Neumane se profesaban mutuo respeto -como se advierte en las propias palabras de Zapiola-, de hecho con el No 10 del Semanario Musical se publicó la Polka Alaide de Neumane. Esta obra está grabada por la destacada pianista Elvira Savi en el disco compacto Isidora Zegers y su tiempo (Santiago:Universidad de Chile, Facultad de Artes, Sello Par-Media, producto artístico, 2003).

32 Guerra 2006.

33 Todas las fechas de fallecimiento de estos tres personajes están erradas en Sandoval 1911.

34Errázuriz 1994: 50. 
pero el impulso definitivo fue posibilitado por los viajes a Europa, especialmente a Francia, realizados por personajes como Domingo Faustino Sarmiento -fundador de la Escuela Normal de Preceptores en 1842- y el propio José Miguel de la Barra, quienes regresaron a Chile convencidos de las bondades y utilidad de esta enseñanza. Así, la Cofradía estableció en 1845 una escuela de dibujo lineal, una institución de beneficencia destinada a la formación de niños y jóvenes de las clases bajas para adquirir oficio artesanal, pero además para elevar su moral y su patriotismo. En 1849 solicitaron al gobierno de Bulnes el apoyo para establecer una Escuela de Música y Canto que debía ser la base para un Conservatorio Nacional. Este paso se dio al año siguiente y posteriormente se implementaron otras instancias para consolidar la nueva institución. El propio Presidente Bulnes destacó la creación de esta entidad como uno de los logros de su gobierno:

"Otras dos creaciones benéficas y populares datan de ese mismo año de mi administración. Una de ellas es la escuela de pintura, en la que se nota a la par del número creciente de alumnos un aprovechamiento superior a lo que tan poco tiempo ha debido esperarse. Se la ha provisto de una hermosa colección de modelos, y con el fin de estimular este bello arte, al que parece tener disposiciones particulares la inteligencia chilena, se ha empezado a formar por el gobierno una colección de cuadros, recogiendo los pocos de algún mérito que el tiempo y la incuria han perdonado. La segunda es la escuela de música y canto, que establecida por la cofradía del Santo Sepulcro en 1849, se erigió el año siguiente en conservatorio de música con fondos nacionales, y con la obligación de dar lecciones gratuitas a toda clase de personas y particularmente a la juventud que se educa en el instituto de Santiago".

(Discurso del Presidente Bulnes al finalizar su mandato, redactado por Andrés Bello).

En primera instancia, se aprecia que se trataba de un proyecto afín al de la escuela de la Sociedad de la Igualdad, donde individuos de distintas clases sociales podían concurrir para recibir formación artística y musical. ¿Por qué la oposición de Zapiola? A mi entender, esto se debería básicamente a los siguientes motivos:

1. La Escuela de la Cofradía apuntaba a la formación de músicos-artesanos y no de músicos profesionales-letrados como lo hacían los Conservatorios europeos.

2. Las decisiones eran tomadas por personas ignorantes en materia de música que no se asesoraban por los expertos verdaderos (como Zapiola).

3. La Escuela de la Cofradía se vinculaba con la elite dominante y su ideología, la escuela de la Sociedad difundía nuevos valores fundados en la soberanía de la razón y del pueblo.

1. Respecto al primer punto, la siguiente crónica publicada en El Mercurio de Valparaíso ${ }^{35}$, donde se menciona tanto a Palazuelos como al primer director del Conservatorio -entonces aún "Escuela de Música y Canto"-, Adolphe Desjardi[s] Ganbairs, nos orienta vívidamente sobre los inicios de este establecimiento:

"Escuela de música

Hemos tenido el placer de asistir a la quinta lección de música vocal dada a sus discípulos por M. Desjardin. El método del profesor nos ha parecido inmejorable, y proporciona tanto

35El Mercurio (Valparaíso), $\mathrm{N}^{\circ} 6634$ (17 de noviembre, 1849). 
entretenimiento a los que aprenden, que estamos seguros de que de día en día irá creciendo el número de concurrentes que es en la actualidad de setenta y cinco.

La Municipalidad ha dispuesto que de cada una de sus escuelas asista a la de música cierto número de niños, siendo de su resorte el costearles los gastos.

Los alumnos de la escuela de Desjardin son casi todos de humilde condición: muchos son aprendices de oficios y cursantes de la clase de geometría y dibujo lineal establecida por los directores de la Cofradía del Santo Sepulcro. Estos jóvenes están sentados según sus edades, empezando por los más tiernos, para dar armonía a las voces e introducir más orden en la escuela.

Una pizarra con rayas blancas para escribir la solfa, y un piano de voces altas, son los únicos enseres de la clase fuera de los asientos. El maestro escribe una serie de notas, llama por sus números, al acaso, a sus discípulos y estos repiten el nombre musical de los signos. Después de esto, empieza el primer banco a dar valor vocal a los mismos signos, siguiendo el piano y la medida que les comunica el profesor. Enseguida las voces del segundo banco se unen a las del tercero, el tercero a las de este último, y así consecutivamente, hasta levantarse un inmenso coro de muchas y variadas entonaciones.

La persona más distraída no podrá menos, al presenciar aquel espectáculo, que comprender inmediatamente la influencia que en la cultura, en la morigeración del carácter, en la moralidad de la vida de aquellos pobrecitos niños, debe ejercer el ejercicio del canto que mueve y educa tanto la porción afectiva del hombre.

En la quinta lección que es la que presenciamos el miércoles en la noche, había ya agrado al escuchar el canto de aquellos niños, y puede asegurarse que dentro de un mes será digna la escuela de ser visitada por las personas que se interesen en la instrucción.

Al nombre de M. Desjardin, debemos acompañar el del señor Palazuelos, como fundadores de tan útil establecimiento. Deseamos que sus tareas sean recompensadas y apreciadas".

Esta observación del cronista de El Mercurio es corroborada por Zapiola tres años después, en el No $8^{36}$ del Semanario Musical:

"Por el honor de nuestro país i del arte, al cultivo i engrandecimiento del cual hemos contribuido en cuanto ha estado de nuestra parte, no habiamos tratado en nuestro periódico sino mui a la lijera de este establecimiento [el Conservatorio], con cuyo nombre aun no han podido atinar ciertas personas. Ellas lo nombran alternativamente, Escuela, Academia, Orfeón i Conservatorio. Decididamente parece que ahora se han aferrado del último, sin duda por ser el que menos le conviene; pues ciertamente no hai una ridiculez igual a la de llamar Conservatorio de música a un establecimiento en que apenas se da lecciones de canto elemental, es decir de solfeo".

Nótese el tono de las primeras palabras del párrafo, donde Zapiola menciona que "ha contribuido en cuanto ha estado de nuestra parte" al "honor de nuestro país y del arte", donde alude seguramente no sólo a su carrera musical sino a la mencionada condición suya de "soldado de la Independencia" y tácitamente a su militancia en la Sociedad de la Igualdad. De lo que sigue, se infiere que a Zapiola no le hubiese molestado mayormente que el establecimiento de la Cofradía se llamara simplemente "Escuela de Música y Canto", sino que se le otorgara el nombre y rango de "Conservatorio de Música". Para merecer este último nombre, se requería una malla curricular más amplia, que se enfocara en la formación de verdaderos músicos letrados, y probablemente en esa dirección apuntaba el plan que el propio Zapiola esbozó y envió a El Mercurio, según afirma en el Semanario Musical, $\mathrm{N}^{\circ} 4^{37}$, y al que lamentablemente no hemos tenido acceso.

36 Semanario Musical, $\mathrm{N}^{\circ} 8$ ( 29 de mayo, 1852), p.1.

37 Semanario Musical, $\mathrm{N}^{\circ} 4$ (1 de mayo, 1852), p.1. 
2. Sobre el segundo punto, cabe indicar que originalmente se dispuso la constitución de una Comisión Superior para supervisar la marcha del Conservatorio. Los primeros miembros de esta Comisión fueron De la Barra, Palazuelos y Gandarillas ${ }^{38}$, los líderes de la Cofradía con los cuales Zapiola compartió diversas instancias ${ }^{39}$, pero de los que se ignora su grado de competencia musical. Sin embargo, en el lapso de dos años estos tres personajes fallecieron, de tal modo que en 1852 la Comisión Superior estaba integrada por otras tres personas que Zapiola individualiza por sus iniciales: "Pbro. V. T.", "N. T." y "S. C.". El propio músico devela que el apellido de "S. C." corresponde a Salustio Cobo. Isidora Zegers en sus notas manuscritas nos proporciona la identidad completa tanto de "S. C. (Cobo)" como de "Pbro. V. T.".

"S. Cobo" es el escritor Salustio Cobo Gutiérrez, del cual no hay indicios de algún tipo de conocimiento, destreza o práctica musical, lo que corroboraría la observación de Zapiola. En cuanto al "Pbro. V. T.", se trata del sacerdote Vicente Tocornal Velasco (18231857). Éste era sobrino del ministro Joaquín Tocornal Jiménez -al cual Zapiola dedicó la partitura del denominado Himno de Yungay - primo y cuñado del abogado Manuel Antonio Tocornal Grez - ministro y segundo Rector de la Universidad de Chile, al que hace referencia Zapiola en sus "Apuntes" en el No 4 del Semanario Musical- y miembro de la Facultad de Teología de la Universidad de Chile. Tocornal culminaría su carrera eclesiástica al ser elegido Obispo de Ancud en 1853, pero es interesante notar que en el momento histórico al que nos referimos este sacerdote probablemente ya era miembro del Cabildo Eclesiástico de la Catedral de Santiago, lo que implica que formaba parte del coro que los integrantes de esta institución formaban para acompañar - con canto llano- los ritos oficiados por el obispo o arzobispo ${ }^{40}$. Por lo tanto, Tocornal necesariamente participaba con regularidad en una práctica musical, pero seguramente no era un músico letrado, no sabía de notación musical ni conocía suficientemente otro tipo de prácticas o repertorios musicales, lo que motivó que Zapiola lo incluyera en su crítica. Por lo demás, en el Semanario Musical, $\mathrm{N}^{\circ} 7^{41}$, Zapiola afirma que el único clérigo tanto en Santiago como en toda la república que en ese momento conocía bien el canto llano era el sochantre Mendoza, lo que implica -por silogismo- que Tocornal tampoco era competente en esta materia, según Zapiola ${ }^{42}$ :

"Nos parece llegado el caso de hacer saber a nuestros lectores el pequeño inconveniente que tienen los tres $\mathrm{S}$. S que componen la COMISION SUPERIOR para el ejercicio de sus funciones. NO CONOCEN UNA NOTA DE MÚSICA $₫$. Falso, nos dirán: ¿cómo es creíble que una Comisión que se encarga de resolver cuestiones entre profesores de música; de ejercer la inspección de las clases de música en los colejios; de aprobar el plan de estudios i ejercicios de música; i de representar al gobierno cuanto sea conveniente para prevenir los abusos de ejecución musical, no sean los hombres más consumados en la ciencia? Pues señor, hemos dicho la verdad i hemos nombrado las personas; que alguno nos pruebe lo contrario[...]".

De este modo, Zapiola señala directamente la gran debilidad de los miembros de la Comisión Superior del Conservatorio: no son músicos letrados y carecen de asesoría de quienes lo son, como el caso de Zapiola. Incluso, si conectamos esta crítica con el comentario mencionado sobre el canto llano en Chile, es posible que el blanco más

38Decreto del 26 de octubre de 1849. Reproducido en Sandoval 1911:8.

${ }^{39}$ Como la participación en el jurado de la Exposición de 1849.

40De Ramón 2002: 57.

41 Semanario Musical, No7 (22 de mayo, 1852), p. 1.

42Los signos y mayúsculas en el párrafo corresponden a la misma semiología usada por Zapiola, tal como se publicó en el Semanario Musical. 
directo sea Tocornal en su relación con el Cabildo de la Catedral. Menciono esto porque uno de los integrantes del Cabildo, el que sigue en jerarquía al Obispo, al Deán y al Archidiácono, es el Chantre, literal y originalmente el "cantor", director del canto, pero que a menudo carecía de las aptitudes necesarias y por ello se limitaba a escoger a un sochantre, un "segundo de a bordo" con la competencia requerida para asumir adecuadamente la dirección musical. Si el Cabildo de la Catedral de Santiago tenía al sochantre Mendoza, ¿por qué la Comisión Superior del Conservatorio no buscaba asesoría técnica, de músicos letrados para ejercer su labor?

3. Sobre el tercer punto, el mismo Salustio Cobo pronunció un discurso el día de la instalación del Conservatorio, que en parte decía:

“[...] el Conservatorio de Música lleva a los mismos resultados por medio de la pasión de las armonías, que a los que alcanza la Iglesia por medio de la pasión de Dios, i la milicia por la pasión de los combates. Cuando vemos a los alumnos de su escuela con la vista fija en la vara del compás, i obedeciendo a todos sus movimientos; cuando observamos esas almas identificadas por una misma emoción, ajitándose en un mismo sentido, i exhalando un mismo i único aliento, diríase que estamos oyendo las preces del clero católico, que en unísonos acentos se elevan bajo la dirección del Pontífice, o presenciando las evoluciones de un ejército, que uniformemente se operan a la voz del jeneral ${ }^{43}$."

Estas imágenes eclesiásticas y militares evocadas por Cobo corresponden a la ambigüedad que el primer Reglamento del Conservatorio, aprobado el 29 de enero de 1851 , otorgaba a esta institución. Esta ambigüedad llevó a Isidora Zegers a presentar su renuncia a la presidencia de la Academia adjunta ${ }^{44}$, noticia que suscitó el comentario de un cronista de $E l$ Diario $^{45}$ y que lo condujo a identificar dicha ambigüedad así:

"El conservatorio de música ¿Es militar o es religioso? ¿Es una institución nacional o es la dependencia de una cofradía? He aquí la cuestión. Los alumnos del conservatorio visten uniforme y fusil a tiempo que tremolan en su bandera la cruz de la redención; se educan para formar las bandas de los cuerpos militares a tiempo que se les prohíbe toda música lírica y marcial.

Entendámonos pues. Es preciso que se defina claramente si el conservatorio es macho o hembra, si es militar o eclesiástico, porque con ese carácter epiceno que su reglamento le atribuye nunca pasará de ser una anomalía flagrante, un contrasentido en que bailan dos principios opuestos atados por la cola, una amalgama en fin soberanamente ridícula".

Zapiola recoge este comentario en el Semanario Musical, $\mathrm{N}^{\circ} 13^{46}$ en términos coincidentes y donde plantea claramente su postura:

"Por lo visto, el corresponsal es de opinión i con sobrado fundamento, de que el reglamento necesita reforma. El reglamento debe hacerse de nuevo, no por abogados o literatos, si no por músicos, i nada mas que por ellos, sean profesores a aficionados. El actual reglamento que no es otra cosa que un hacinamiento de palabras sin sentido, solo puede servir de materia de risa para los conocedores, pues en cada línea, en cada palabra se descubre la completa ausencia de los conocimientos rudimentales del arte".

43 "Instalación del Conservatorio", El Telégrafo (Santiago, 27 de septiembre, 1852), p. 2, reproducido en Errázuriz 1994: 57.

44La carta manuscrita de renuncia de Isidora Zegers está en el álbum conservado entre los papeles de Eugenio Pereira Salas. En esta misma fuente hay una copia de este primer Reglamento del Conservatorio, en cuya primera hoja, en el extremo superior derecho, la mencionada dama escribió, en alusión a este documento:"Malo y ridículo, y al que no me era posible conformarme, por lo cual di mi renuncia a la presidencia de la corporación". 45 El Diario ( 24 de junio, 1852).

46 Semanario Musical, $\mathrm{N}^{\circ} 13$ (3 de julio, 1852), p.1-2. 
Muy interesante es el modo en que Zapiola sitúa a los "músicos" en el mismo rango que los abogados o literatos, es decir, los letrados por excelencia, pero hay que hacer hincapié en que no se trata de cualquier tipo de músicos sino de profesores (músicos profesionales) o aficionados, músicos letrados, alfabetizados y competentes. Frente a las preguntas del corresponsal, Zapiola responde "De todo tiene i es todo, menos lo que indica su nombre", lo cual desarrolla en los siguientes párrafos. Y hacia el final, Zapiola va más allá y no solamente plantea por qué la Escuela de la Cofradía no puede ser llamada "Conservatorio", sino por qué un verdadero Conservatorio sería una institución inútil en el país:

"Cuando se dice que el fin del Conservatorio es principalmente la educación del pueblo, se asienta una cosa impracticable: estos establecimientos solo son para los pueblos en que hai necesidad de profesores, es decir para cinco o seis pueblos europeos de primer orden; hasta ahora a nadie se le había ocurrido formar músicos para proporcionarles un recurso cómodo para morirse de hambre. Chile no necesita músicos, pues tiene de sobra todos los que han emigrado últimamente, i los que tendrán que hacerlo mui pronto. Quisiéramos que se contestase a esta sola pregunta -dado el caso de que ese establecimiento formara buenos profesores, que harían ¿dónde encontrarían ocupación?

Los que sostengan la permanencia del Conservatorio, indaguen cuál es la situación de la mayor parte de los músicos, i veran cuánto callamos acerca de los sufrimientos de algunos de ellos en estos últimos tiempos, ¡no ciertamente por falta de aptitudes!”

Los "sufrimientos" a los que alude Zapiola deben entenderse en la línea de su argumentación, es decir, la falta de ocupación laboral. En los "últimos tiempos", por ejemplo, se había suprimido la orquesta de la Catedral, una de las principales fuentes de trabajo de los músicos en Santiago. Zapiola hizo alusión a este hecho en el $\mathrm{N}^{\circ} 4$ del Semanario Musical y también allí mencionó la estrategia de educación musical que estimaba más conveniente y que reitera en este $\mathrm{N}^{\mathrm{o}} 13$ :

"Repetiremos por última vez que si se quiere difundir la enseñanza de la música en todas las clases de la sociedad, el solo modo de conseguirlo es, siguiendo el sistema único reconocido como eficaz, enseñarla en las escuelas a la par con los otros ramos de educación.

Esperamos que el gobierno, desengañado como ya debe estarlo de la equivocación que ha sufrido en la creación de este establecimiento, quiere tomar el solo i verdadero camino en este asunto, no proceda sin consultar personas inteligentes $i$ desinteresadas.

Si tres años de experiencia no es suficiente desengaño, no sabemos cual lo sea".

Pasarían casi cuarenta años antes que este planteamiento sobre la educación musical se realizara, cuando la reforma educacional de 1893 impuso la enseñanza de la música en todas las escuelas del país. Zapiola no alcanzó a ver esto, pero sí pudo presenciar, algunos meses después de escribir sus críticas, la redacción de un nuevo reglamento más coherente, como recuerda Pereira Salas ${ }^{47}$ :

"El nuevo director del Conservatorio ${ }^{48}$, don José Vicente Sánchez, encargó al escritor Rafael Minvielle, la redacción de un reglamento orgánico que eliminara algunas de las inconsecuencias y exageraciones doctrinarias del decreto de enero de 1851. Fue entregado el 18 de enero de 1853 , y en sus artículos que respetan la estructura inicial de una escuela de música y de un Conservatorio como instituciones básicas, se abandonan ciertas normas cívicas aplicadas a la música y se insiste algo más en el aspecto puramente artístico de dicha disciplina”.

47Pereira Salas 1957: 93-94.

48Más bien el nuevo presidente de la Academia del Conservatorio, el puesto que tenía Isidora Zegers y al que había renunciado, en tanto el puesto de director del Conservatorio continuó en manos de Desjardins. 
Sin duda la labor crítica de Zapiola contribuyó a que la opinión pública cayese en cuenta sobre el asunto y esto facilitó el cambio del reglamento del Conservatorio. Pocos meses después, aquél que tan duramente había criticado al Conservatorio Nacional de Música -en un tono que no deja de recordar en algo a Sarmiento-, asumió cono Subdirector del establecimiento e incluso llegó a ser Director del Conservatorio entre 1857 y 1858. Desde estos puestos prosiguió los esfuerzos para mejorar la calidad del Conservatorio de Música, si bien no logró eliminar de la fachada del edificio el título "Batallón Cívico $\mathrm{N}^{\mathrm{o}}$ 2", una de las últimas secuelas del complicado origen de la institución ${ }^{49}$. Así, en 1869, un corresponsal del periódico Las Bellas Artes -especie de heredero del Semanario Musical- expresa lo siguiente respecto a esta institución ${ }^{50}$ :

"Ayer domingo, el Presidente de la República [José Joaquín Pérez] distribuyó con gran pompa, en el Teatro Municipal [el antiguo recinto, anterior al incendio de 1870], los premios que el jurado acordó a los señores que presentaron los mejores objetos en nuestra primera Exposición de agricultura.

La parte musical fue magnífica. Todos los alumnos y alumnas del Conservatorio de Música, en número de ochenta, ejecutaron, dirigidos por su inteligente director don Francisco Oliva, la canción nacional de Carnicer, la obertura de la Hija del Regimiento y el hermoso himno a la Industria, compuesta por el mismo señor Oliva. Este himno que escuchábamos por primera vez, a pesar de haberse cantado ya en otra ocasión, es una de esas composiciones que están llamadas a inmortalizarse.

La elegante poesía de don Guillermo Matta ha inspirado al músico pensamientos felices. La melodía es agradable y fácil sin ser trivial.

De la estrofa al coro se modula con naturalidad y gracia para entrar a un tutti fortissimo de grande efecto.

Los ochenta ejecutantes, con excepción de tres o cuatro, todos han sido o son alumnos del señor Oliva.

Muchos de ellos son ya buenos profesores que a su vez propagan el divino arte que aprendieron en el Conservatorio.

La repartición de premios de la Exposición ha proporcionado una bella oportunidad al señor Oliva para que el país aprecie en una sola vez el resultado espléndido de los asiduos trabajos de largos años. Ahora que el Gobierno ha podido dar, merced al Conservatorio tanta brillantez a una fiesta nacional, no se dirá que el Conservatorio debe suprimirse por ser una partida de lujo en el presupuesto. Esta peregrina ocurrencia la tuvo hace dos años un diputado. Sin el Conservatorio no tendríamos orquesta en el teatro, ni música en nuestros templos, ni en la Filarmónica, ni en nuestras fiestas de familia, o a lo más tendríamos una pobre música. Los que no tenemos las orejas de Midas pedimos, por el contrario, que se fomente esa importante escuela, aumentando un poco más la triste cantidad que se le designa todos los años. El Gobierno, como lo acaba de palpar, tendrá siempre a su disposición una numerosa y brillante falange de músicos, sin necesidad de desembolsar un centavo. Por otra parte, cada uno de esos jóvenes, ya sean hombres o mujeres, tiene una familia que sostener, y la sostienen, en efecto, con su noble y honrosa profesión. Estas familias son familias chilenas como cualesquiera otras. ¿Dónde está pues, ese lujo que debe ser suprimido? Cuando no se piensan las cosas se dicen muchos disparates".

Es probable que esta crónica haya sido redactada por Juan Jacobo Thomson, director de Las Bellas Artes y una especie de discípulo de Zapiola que gestionó la publicación en esta misma revista de la Canción Nacional de Manuel Robles -nótese la mención de la "canción nacional de Carnicer" y no "Canción Nacional" a secas- que Zapiola recordaba y accedió a transcribir. El mencionado Francisco Oliva fue discípulo de Zapiola y su sucesor como Director del Conservatorio, cargo que ejerció hasta su muerte en 1872.

49 Pereira Salas 1957: 97.

50 Las Bellas Artes, No 15 (12 de julio, 1869), p.123. 
Otro ilustre discípulo suyo fue Manuel Jesús Zubicueta, el cual se formó como músico -cantante-, profesor normalista y como dibujante ${ }^{51}$, es decir, dentro del ideal educacional de la Cofradía del Santo Sepulcro. Zubicueta tuvo una carrera en la ópera y fue autor de un Catecismo Teórico-Musical, obra que usó en sus clases de teoría y solfeo en el Conservatorio $^{52}$ y que reflejan la enseñanza de Zapiola ${ }^{53}$. El propio Zapiola, como se ve, terminó manifestando aprecio a esta institución, pero hasta el fin de sus días lamentó el escaso apoyo que recibía por parte del Estado, como expresa en esta cita de sus Recuerdos de treinta años:

"Hay escuela de pintura, de escultura, etc.: ¿cuál de estos establecimientos presta servicios
tan útiles y benéficos como el Conservatorio? Ninguno. Baste decir que esta institución es
la única en que tienen parte las mujeres, que la ocupan en su mayor parte, proporcionando
a gran número de familias pobres una profesión que las pone a cubierto de la miseria y el
vicio [...].
Hemos sido profesor, director y presidente del Conservatorio. A todo hemos renunciado; no
por la escasez o absoluta falta de honorario, sino por el desdén con que, con pocas excepciones,
es mirado, llegando el caso de haber Ministro que no ha sabido dónde está situado [...]. No
faltan personas que piensan que sólo sirve para divertir a los que aprendan [...].
¡Pobre Conservatorio! ¡Pobre música! ¡Qué de sopapos habéis recibido en estos días!”

\section{PERSPECTIVAS.}

Se puede apreciar que el músico José Zapiola afirmó su pertenencia a la ciudad letrada en tanto escribe desde su propia vivencia de la práctica musical. Si la modernidad, en términos de García Canclini, implica un proyecto emancipador, Zapiola participó no solamente en la gesta de la emancipación nacional, sino en el esfuerzo por la emancipación del músico en tanto miembro activo y competente de la ciudad letrada y además en una emancipación de sí mismo como persona y como ciudadano, con todo su trasfondo de ilegitimidad social que buscó superar desde su oficio y su preocupación social. Desde allí, desde su actividad como músico letrado, Zapiola escribe sobre su pasado y su presente, lo que lo convierte en fundador de un linaje específico de crítica musical en Chile y en fundador de la historiografía de la música en Chile, no solamente en lo que atañe al aporte de documentos o datos, sino en tanto realizó una crítica de la institucionalidad musical. En su "crítica de la crítica", fundamentada en la situación actual de esta actividad en Chile, Spencer ${ }^{54}$ dice lo siguiente:

"Para lograr convertirse en un motor del 'desarrollo musical del país' es indispensable que la crítica y los críticos dejen de percibirse a sí mismos como actores poco relevantes del proceso de educación musical (esto es, como meros trabajadores de un medio) y logren asignarle mayor valor a su actividad".

No me cabe duda que Zapiola, uno de los fundadores de la crítica musical en Chile, no se percibía para nada como un "actor poco relevante" en el proceso no sólo de la educación musical, sino de la formación de la cultura republicana chilena. El huacho autodidacto, el soldado de la Independencia, "sujeto adánico de los albores de la

51Una litografía suya fue enviada a la Exposición Universal de París de 1867. Referencia en http://www.mac.uchile.cl/catalogos/anales/paris.htm [último acceso, 4 de marzo de 2008].

52Sandoval 1911: xvi. Un joven alumno suyo fue el compositor Pedro Humberto Allende.

53Pereira Salas 1945: 302.

54Spercer 2004: 8. 
República", tenía muy claro su valor y su pertinencia al hablar sobre el campo que más conocía, la música. Aunque ciertamente hay una gran diferencia entre su labor y aquella similar que realizan los críticos de música en la actualidad, y es que Zapiola logró tener su propio medio independiente de expresión, el Semanario Musical, una posibilidad que los críticos contemporáneos raramente consiguen.

Concluyo con dos citas de Zapiola que apuntan además hacia su futuro, nuestro presente. La primera corresponde al final de un comentario suyo en el Semanario Musical $\mathrm{N}^{\circ} 8^{55}$ :

"Sea de ello lo que fuere; estamos ciertos de que si nuestros apuntes llegan ser leídos por algun historiador de la música chilena, i ve como se procedia con este pobre arte a mediados del siglo 19, esclamará con el sabido oh témpora!!!!!!!!!!!!!!!”

Y la segunda procede de la carta del 27 de febrero de 1872 a don José B. Suárez ${ }^{56}$, quien le solicitó una reseña biográfica para su obra Plutarco del joven artista:

"Cediendo a sus repetidas instancias para que le proporcione algunos datos sobre mi pobre vida de artista, lo hago sólo para complacerle y por dejar constancia de ciertos hechos que más tarde pueden servir cuando algún amante de la música quiera escribir algo sobre su historia en Chile".

\section{BIBLIOGRAFÍA}

Diarios

El Diario (24 de junio, 1852).

Semanario Musical (1852), No 1-16. Santiago: Imprenta de Julio Belin y Cía.

\section{II}

Amunátegui Aldunate, Miguel Luis

1872 Los precursores de la independencia. Santiago: Imprenta de la República. Tres volumenes.

1888 Las primeras representaciones dramáticas en Chile. Santiago: Imprenta Nacional.

1892 La alborada poética de Chile: después del 18 de setiembre de 1810. Santiago: Imprenta Nacional.

BARTH NEIMAN, LIVIA

1970 José Zapiola y el Semanario Musical. Memoria presentada para optar al grado de Licenciado en Artes y Ciencias Musicales, mención Musicología. Profesor guía: Samuel Claro Valdés. Santiago: Universidad de Chile.

55 Semanario Musical, $\mathrm{N}^{\circ} 8$ (29 de mayo, 1952), p.1, c.3.

56 Suárez 1872. 
De RAMÓN ACEVEDO, EMMA

2002 Obra y fe. La catedral de Santiago: 1541-1769. Santiago: DIBAM, Centro de Investigaciones Diego Barros Arana, LOM.

DÍAZ-CID, CÉSAR

2002 "El sujeto adánico dislocado: los Recuerdos de Treinta Años de José Zapiola", Revista Chilena de Literatura, $\mathrm{N}^{\circ}$ 61, pp.191-207.

2004 "Sujeto adánico en la construcción del discurso nacional chileno: los Recuerdos de Treinta Años de José Zapiola”, Literatura y lingüística [online], No 15, pp.47-66. Disponible en la WWW: http://www.scielo.cl [citado 03 de enero 2006].

DYSON, JOHN P.

1965 La evolución de la crítica literaria en Chile. Santiago: Editorial Universitaria.

ERRÁZURIZ LARRAÍN, LUIS HERNÁN

1994 Historia de un área marginal: La enseñanza artística en Chile, 1797-1993. Santiago: Ediciones Universidad Católica de Chile.

GAZMURI, CRISTIÁN

1992 El "48" chileno: igualitarios, reformistas, radicales, masones y bomberos. Santiago: Editorial Universitaria.

GRANDELA DEL RÍo, Julia InÉS

1999 “Crítica musical (III-Chile)". Diccionario de la música española e hispanoamericana. Tomo IV. Madrid: Sociedad General de Autores y Editores, p. 183.

Guerra Rojas, Cristián

2006 "La música en los inicios de los cultos cristianos no católicos en Chile: El caso de la Union Church (Iglesia Unión) de Valparaíso, 1845-1890”, Revista Musical Chilena, LX / 206 (julio-diciembre), pp. 49-83.

MERINO MONTERO, LUIS

1981a “Don Andrés Bello y la música”, Revista Musical Chilena, XXXV/153-155 (eneroseptiembre), pp.5-51.

1981b "Don Andrés Bello y la música", Revista Musical de Venezuela, II/5 (septiembrediciembre), pp.13-68.

1982 "Don Andrés Bello y la música", Homenaje a Don Andrés Bello. Santiago: Instituto de Chile y Editorial Andrés Bello, pp.187-234.

MONTECINO Aguirre, SONIA

1993 Madres y huachos. Alegorías del mestizaje chileno. Segunda edición. Santiago: Cuarto Propio-CEDEM.

Pereira Salas, Eugenio

1941 Los orígenes del arte musical en Chile. Santiago: Imprenta Universitaria.

1945a “José Zapiola Cortés (1802-1885)", José Zapiola Cortés. Recuerdos de Treinta Años. Octava edición. Santiago: Zig-Zag, pp.9-36.

1945b "Bibliografía”, José Zapiola Cortés. Recuerdos de Treinta Años. Octava edición. Santiago: Zig-Zag, pp.299-303.

1957 Historia de la música en Chile (1850-1900). Santiago: Publicaciones de la Universidad de Chile.

PÉREZ RosAles, VICENTE

1886 Recuerdos del pasado, 1814-1860. Tercera edición. Santiago: Imprenta Gutenberg. 
RAMA, ÁNGEL

1984 La ciudad letrada. Santiago: Tajamar Editores.

SANDOVAl Bustamante, LuIS

1911 Reseña histórica del Conservatorio Nacional de Música y Declamación: 1849-1911. Santiago: Imprenta Gutenberg.

SPENCER ESPINOSA, CHRISTIAN

2004 "La crítica musical en Chile: reflexiones sobre un oficio en transición”. Resonancias, No 14 (mayo), pp. 5-11.

STUVEN VATTIER, ANA MARÍA

2000 La seducción de un orden: las élites y la construcción de Chile en las polémicas culturales y políticas del siglo XIX. Santiago: Ediciones Universidad Católica de Chile.

SUÁREZ, JOSÉ BERNARDO

1872 Plutarco del jóven artista. Tesoro de Bellas Artes. Santiago: Imprenta Chilena.

URRUtia BLONDEL, JORGE

Sf. José Zapiola Cortés. Estudio inédito.

1973 "La música en el siglo XIX”, Samuel Claro Valdés y Jorge Urrutia Blondel, Historia de la música en Chile. Santiago: Orbe, pp.83-116.

WALKER MARTÍNEZ, CARLOS

1888 Historia de la administración Santa María. Tomo I. Santiago: Imprenta de El Progreso.

ZAPIOLA CORTÉS, JOSÉ

1902 La Sociedad de la Igualdad y sus enemigos. Guillermo Miranda (editor). Santiago: Imprenta Enrique Blanchard-Chessi.

1945 Recuerdos de treinta años. Edición electrónica disponible en la WWW:

http://www.historia.uchile.cl/. [citado 03 de enero 2006]. 